\title{
Mito de Orfeu em Um Trem para as Estrelas: a canção e o filme
}

\author{
Jussara Bittencourt de Sá*
}

\begin{abstract}
Resumo
Este estudo apresenta uma análise sobre a presença do Mito de Orfeu, a partir dos os aspectos inter e intratextuais nas obras (canção e filme) Um Trem para as Estrelas. O recorte teórico utilizado está pautado nas reflexões sobre a linguagem literária e cinematográfica, com ênfase na teoria bakhtiniana da heteroglossia, do dialogismo, da polifonia e da carnavalização. O filme produzido em 1987, dirigido por Carlos (Cacá) Diegues Um Trem para as Estrelas, o filme, coloca em cena a odisseia de Vinícius/Vina (Guilherme Fontes) à procura de sua amada Eunice/Nicinha (Ana Beatriz Witgen), e a busca de sua consagração como músico. A canção homônima "Um Trem para as Estrelas" foi criada por Cazuza em parceria com Gilberto Gil, com objetivo compor a trilha sonora do referido filme. Na análise procura-se também avaliar a presença da persona Cazuza, na medida em que atua como personagem representando o artista Cazuza. Destaca-se também que a ironia aparece nas linhas das urdiduras que contribuem para a tessitura das obras. Constatou-se, pela consonância versos/cenas, a maneira peculiar em que o Mito de Orfeu aparece desenhado no poema/música e filme/imagens.
\end{abstract}

\section{Palavras-chave}

Cinema. Música. Mito de Orfeu.

Estudar a arte pode ser instigante e reflexivo. É através da arte que os recônditos mais originários da vida aparecem desvelados. Ao adentrar por camadas profundas e enigmáticas do humano, as obras trazem à cena as singularidades da vida, vivida ou imaginada. Segundo Langer "A arte [...] pode ser definida como a prática de criar formas perceptíveis expressivas do sentimento humano." (LANGER, 1981 , p. 82). Pode-se afirmar ainda que a arte vem se desenhando como uma forma de expressão e de conhecimento humano com presença fundamental e expressiva na dinâmica das diferentes culturas.

\footnotetext{
* Doutora em Literatura pela Universidade Federal de Santa Catarina. Professora titular da Pósgraduação em Ciências da Linguagem e do curso de Letras da Universidade do Sul de Santa Catarina
} 
Assim sendo, é pela esteira do pensamento de a arte é um conhecimento pontuado que contempla, em seus modos de expressão, a ideia e a pratica enquanto representação da vida, que se desenvolve o presente estudo sobre as obras: Um Trem para as Estrelas, canção e filme. Procura-se analisar o trânsito do Mito de Orfeu a partir dos os aspectos inter e intratextuais. Para a descrição e abordagem das obras recorrem-se as referências sobre a linguagem literária e cinematográfica. As reflexões para análise das obras homônimas aportam-se, dentre outras, na teoria bakhtiniana da heteroglossia, do dialo gismo, da polifonia e da carnavalização.

Um Trem para as Estrelas, o filme, coloca em cena a odisseia de Vinícius/Vina (Guilherme Fontes) à procura de sua amada Eunice/Nicinha (Ana Beatriz Witgen), e a busca de sua consagração como músico. Foi produzido em 1987, dirigido por Carlos (Cacá) Diegues, com elenco principal, além de Guilherme Fontes e Ana Beatriz Witgen: Milton Gonçalves, Taumaturgo Ferreira, Zé Trindade, Mirian Pires, Flávio Santiago, Tânia Bôscoli, Betty Prado, Paulão, Cristiana Lavigne, Ezequiel Neves, Yolanda Cardoso, Marcos Palmeira, e as participações especiais de José Wilkner, Betty Farias, Daniel Filho e Cazuza.

A canção "Um Trem para as Estrelas" foi composta por Cazuza em parceria com Gilberto Gil, para se tema, fazendo parte, assim, da trilha sonora do referido filme.

Percebe-se que a consonância do poema/música e filme/imagens acontece, através dos versos/cenas compostos por rimas perfeitas e imperfeitas, internas e externas e, ironicamente, pelo inconformismo/conformismo, protagonista/poeta diante da sua realidade urbana. Tais aspectos evidenciam o caráter dialógico que transcorre entre a temática dos versos da canção e a representação das personagens e o enredo do filme.

A canção Um Trem para as Estrelas:

São sete horas da manhã

Vejo o Cristo da janela

O sol já apagou sua luz

E o povo lá embaixo espera

Nas filas de ponto de ônibus

Procurando onde ir/São todos seus cicerones

Correm para não desistir

Dos seus salários de fome

E a esperança que eles têm

Nesse filme como extras

Todos querem se dar bem

Num trem para as estrelas

Depois de navios negreiros

Outras correntezas

Estranho o teu Cristo, Rio

Que olha tão longe, além

Com braços sempre abertos

Mas sem proteger ninguém

Eu vou forrar as paredes

No meu quarto de miséria 
Com manchetes de jornais

pra ver que não é nada sério

Eu vou dar o meu desprezo

Pra você que me ensinou

Que a tristeza é uma maneira

Da gente se salvar depois.

Os versos desta canção sinalizam para dois lugares de observação do eu lírico em termos de narrativas poéticas. Primeiramente, observando a obra mencionada a partir de uma posição inferior: "São sete horas da manhã/Vejo Cristo da janela." Reportando a linguagem cinematográfica, podemos dizer que a câmera/olhar, estaria numa posição contra-plongée,1, ama vez que a estátua do Cristo Redentor, no Rio de Janeiro situa-se em um dos pontos mais altos da cidade. Porem, na sequência ocorre um deslocamento do foco. "E o povo lá embaixo espera/Nas filas de ponto de ônibus/Procurando onde ir/São todos seus cicerones/Correm para não desistir/Dos seus salários de fome." O olhar dirigi-se para baixo, em uma posição plongée, revelando a posição superior do eu lírico sobre o que observa.

No filme, a personagem Vinícius/Vina (músico, saxofonista, pobre, órfão de pai, mãe, dançarina - Betty Farias, vive com um tio, em um minúsculo apartamento de um prédio do subúrbio do Rio de Janeiro), entra na diegese a partir dos créditos.

Assim como a canção, constatam-se duas posições. Primeiramente, Vinícius passa por entre as pessoas que esperam nas filas de ônibus. Ou seja, estaria junto àquelas mencionadas nos versos da canção. A posição inferior reitera-se pela expectativa de ser chamado para uma audição com Cazuza. Na sequencia, a personagem desloca-se ate a cobertura de um edifício. Vinicius toca seu saxofone, ao mesmo tempo em observa de cima (plongée) a cidade. Depois dirige seu olhar para um helicóptero que sobrevoa próximo ao local onde está (contra-plongée). As cenas são apresentadas em do plano geral - PG, ao primeiro plano PP, doravante neste estudo serão utilizadas as siglas dos planos. ${ }^{2}$

Sobre os diferentes ângulos de observação, tanto na canção como no filme, fazse oportuno a abordagem sobre a teoria bakhtiniana do diálogo de Robert Stam. Para este autor, "o que vemos é determinado pelo lugar de onde vemos", portanto, cada olhar é impessoal e subjetivo, e a cada visão caberá o papel de complementar o diálogo. Neste caso, o olhar do poeta complementa e é completado pela imagem e pelo do som do filme, e vice-versa, estabelecendo, assim, a intertextualidade.

\footnotetext{
${ }^{1}$ Plongée, palavra francesa que significa mergulho. A câmera observa os acontecimentos de cima para baixo. Classicamente tem sentido de esmagar. No caso da cena suscitada, seria de inversão, ou seja, de ver os acontecimentos de baixo para cima.

${ }^{2}$ Apresento uma legenda simplificada sobre os planos: PG, Plano geral, mostra o conjunto de um cenário/paisagem; PC, Plano de conjunto, mostra um grupo de personagens; PM, Plano médio, personagem de corpo inteiro; PA, Plano americano, personagem dos joelhos para cima, aproximadamente; PP, Primeiro Plano, mostra o personagem da cintura para cima; PPP, Primeiríssimo Plano, mostra o rosto do personagem; PD, mostra um detalhe do rosto, de uma parte do corpo, de um objeto
} 
O desdobramento do compositor da canção com personagem/persona Cazuza (o artista, personagem que representa a si mesmo) começa, em primeiro plano, a partir da cena do diálogo entre Vinícius/Vina e Dreamer (Taumaturgo Ferreira). Vinícius finalmente é convidado a fazer uma audição com Cazuza. Para ele esse encontro seria a maior chance de sua vida. Tais quais os versos, uma chance de "Se dar bem/Num/trem para as estrelas." A intertextualidade e interdiscursividade desenhamse pelo entrelaçar das linhas da música/filme, Vinícius/Cazuza, escuridão/luz, a luz da estrela.

Numa próxima cena, já no estúdio de gravação Vinicius aparece como saxofone acompanhando Cazuza e demais músicos no estúdio de gravação. Vinicius se empolga durante a musica, ousando com algumas improvisações. Descontentes com o saxofonista os diretores determinam uma parada na gravação. Vinicius é censurado pelos diretores. Na sequencia, Cazuza vai até ele elogiando sua perfomance, mas o repreende: "Deixa eu cantar, bicho. A musica é minha." Vinicius, com a voz baixa, pede desculpas, afirmando que não sabe o porque teve aquela atitude.

Neste diálogo, percebemos o que o ato da fala relaciona as estruturas sociais, e revela, através da polifonia, da entonação (um dos códigos da interação do discurso) que tanto Cazuza quanto Vinícius dão as suas palavras. Conforme Bakhtin, "a palavra está sempre carregada de um conteúdo ou de um sentido ideológico ou vivência." Assim sendo, cada palavra submete-se a pronúncias e entonações diferenciadas, apresentando-se como uma arena em miniatura onde se entrecruzam e lutam os valores.

Ao registrar Cazuza enquanto persona, extraio para a significação de máscara, do Latim. Ocultar a face significaria desvestir-se do individual, de um eu pessoal, para assumir a condição universal de um eu cósmico, máscara em que cada homem se reencontra. Um processo ambíguo e auto-reflexivo, o ser real, essencial, reencontrado no seu, como um espelho. O ser real expresso em própria máscara, para se interpretar, instaurando a dualidade pessoa/persona.

Cazuza aparece na tela, na cena da audição de Vinícius, em plano detalhado $\mathrm{PD}$, com movimento de câmara, transformando em plano médio - PM.

A metalinguagem do cinema acontece, registrada, através de uma câmera gravando o ensaio de Cazuza. A relação dialógica estabelecida pela câmera conduz, novamente à dicotomia Cazuza/persona, Cazuza/Cazuza.

Abro agora para apresentar alguns elementos de Cazuza, neste texto, rastreando alguns momentos de sua vida, na tentativa de esclarecer as entonações dadas por Vinícius, ao pronunciar Cazuza.

A persona que Cazuza auto-interpreta é autor (em parceria com Gilberto Gil), conforme foi colocado anteriormente, da música Um Trem para as Estrelas.

Eduardo Duó, no capítulo "Cazuza, um estudo". O descreve da seguinte maneira:

Bebendo de fontes aparentemente deslocadas da atualidade que vão dos porres antológicos dos beatniks americanos às intermináveis dores - de - cotovelo de Dolores Duran, Cazuza acabou se transformando num dos mais preciosos tradutores dos anos 80 . Não é por menos que sua acachapante poesia é hoje um dos mais bem acabados retratos poéticos do Brasil contemporâneo. (DUÓ, 1990, p. 105). 
Considerado uma espécie de guru dos anos oitenta, Cazuza penetra nessa década, tentando "destrinchar" o caminho, para entender o pensamento dos filhos da "ditadura" do black - out' de 1964.

Apresentando sua poesia de maneira visceral, ele mostra os conflitos da geração que cresceu em frente à televisão, "dividida entre o medo e a ignorância." É dessa ignorância que Cazuza, numa paródia da ironia socrática, quer dar consciência ao seu tempo e as às gerações vindouras, numa interrogação do medo sob a máscara do sarcasmo. Seu primeiro momento foi de rebeldia, nos tempos do Barão Vermelho. Em seu trabalho Ideologia e Burguesia, o engajamento sofisticado provou que dera um boom, um grande salto entre os músicos de sua geração. Sua performance, nos shows dos discos da primeira fase, fora de maneira irreverente. Seus gritos, seu tom de voz, sua expressão corporal, demostravam que Cazuza desafiava, constantemente, os padrões da sociedade burguesa: "Enquanto houver burguesia não vai haver poesia." E é através do domínio de seu corpo e de sua postura perante o público que Cazuza cria a sua personalidade ao virar-se para dentro, refletindo seu interior nesta, cuja característica principal foi a irreverência.

A persona Cazuza, em seu diálogo com Vinícius/Vina, através de suas palavras, deixa transparecer a relação hierárquica domínio do poder.

Bakthin chama de "palavra", ou seja, sob a linguagem no sentido mais amplo, é o fenômeno ideológico por excelência é o meio mais puro e mais sensível de interação social. A palavra está sempre presente, nos discursos, internos ou externos, registrando as faces do processo social. Neste caso, especificamente, fica estabelecida a divisão das castas profissionais e sociais.

Apesar de ficar estabelecida a ordem social, há uma inversão, na frase: "- Deixa eu cantar, pô", de certa forma é o artista, o astro que pede permissão para cantar.

Ao sair da audição, cheio de esperanças, Vinícius procura Eunice/Nicinha (Ana Beatriz Witgen), que é introduzida na diegese do filme, em primeiríssimo plano, numa cena na loja em que ela trabalha, em um shopping, da Zona Sul.

$\mathrm{Na}$ cena Vinícius a puxa para dentro do trocador, comunica as boas novas e confessa seus projetos, beijando-a após.

A personagem Eunice, numa configuração aristotélica, que Beth Brait explicita, reveste-se de dois aspectos essenciais: "a personagem como reflexo da pessoa humana, a personagem como construção, cuja existência obedece às leis particulares que regem o texto." (BRAIT, 1985, p. 29). E a esses dois aspectos, acrescento o conceito de personagem: ente composto pelo poeta, a partir de uma seleção do que a realidade lhe oferece, cuja natureza e unidade só podem ser conseguidas a partir dos recursos utilizados para a criação.

Eunice se revela, através do diálogo com Vinícius, alguém distante e insensível aos sentimentos e aos sonhos do namorado. A noite, Vinícius e Eunice vão ao topo de um morro, onde existe um cemitério de carros velhos. Ele comenta que de longe a cidade é muito mais bonita. Eunice afirma: - é de longe e no escuro. Na continuidade do dialogo: Vinícius - E eu vou ser rico e famoso/Eunice - Cai na real, Vina./Vinicius Sabia que seu corpo também tem um som?/Eunice- Deve ser a minha barriga roncando de fome.

Para Renata Palotini relativamente à personagem, ser de palavras: 
É importante mostrar como se coloca a personagem em relação aos outros homens, de que forma ele se insere no seu grupo: como, portanto, se caracteriza socialmente; situação na sociedade a que pertence. (PALOTINI, 1989, p. 65).

Eunice, após algumas trocas de carinho com Vinícius, desaparece. Esse ato dá é o inicio da odisseia do protagonista. Esta já começa instantes sua procura, após se voltar para trás e perceber sua ausência, quando olhou a pedra em que ela estava sentada. Eunice aproxima-se de Eurídice, e Vinícius, com seu saxofone, de Orfeu com sua lira, o que vem expresso pelo próprio Monólogo de Orfeu:

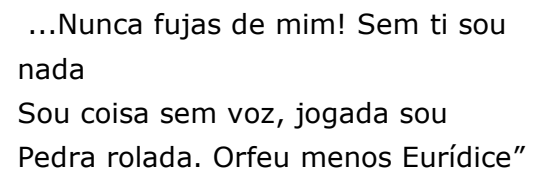

Considerando ser relevante à análise, apresento, a seguir, a história do "Mito de Orfeu".

Orfeu nasceu próximo ao Olimpo, freqüentado pelas musas. É considerado o inventor da cítara, e também um extraordinário cantor, poeta e músico.

Sua voz, ao entoar suas canções, é tão melodiosa que acalmava até mesmos os homens mais rudes, e os animais mais ferozes repousam mansamente a seus pés. Seu canto é capaz de competir com os das sereias, livrando, assim, os marinheiros de seus encantamentos.

É apaixonado por Eurídice, sua noiva, filha de Apolo. No dia de seu casamento, enquanto ela caminhava, Aristeu, tenta violentá-la e, no desespero de livrar-se dele, ela cai e pisa em uma serpente que esta escondida, morrendo ao ser picada.

Orfeu, que jura procurá-la entre os mortos, pega sua lira e desce ao inferno. Sua melodia conquista e enebria os deuses e os mortos, guardiães da porta da morada dos mortos. Comovidos pela paixão Hades e Pérsefone, entregaram-lhe Eurídice, impondo-Ihe a condição de não olhar para ela enquanto não deixassem o inferno. Após concordar, Orfeu começa a caminhar de volta ao mundo dos vivos, seguido por sua amada, que vem logo atrás. Próximo à saída do inferno, a curiosidade de Orfeu é maior, e ele olha para saber se sua amada realmente está ali. No mesmo instante, Eurídice desaparece para sempre do inferno.

Orfeu permanece fiel à Eurídice e evita as mulheres. Estas, revoltadas por sua indiferença, matam-no, lançando pedaços de seu corpo esquartejado ao rio. Sua cabeça e sua lira vão parar na ilha de Lesbos. Os habitantes fazem-lhe um túmulo de onde, muitas vezes, contam, sai o som da lira de Orfeu.

Retornando ao filme, já na delegacia, Vinícius, como Orfeu, que chegou a tocar com a "Estrela", chega ao inferno e, em primeiríssimo plano, começando a procura de sua amada. A construção da personagem Eunice é decorrente da composição de informações obtidas pelos diálogos ao longo da historia, durante a diegese.

O diálogo entre Vinícius e o delegado, Dr. Freitas (Milton Gonçalves), expressa, em todo conjunto de códigos que fazem parte de diegese, principalmente pelas palavras do delegado dirigidas a Vinícius, a hierarquia da "relação social", mas 
precisamente de poder, perante à situação, confirmada pela frase imperativa do delegado: - "Vem cá garoto." Para Bakthin "[...] a realidade determina o signo, o signo reflete e refrata a realidade em transformação." (BAKTHIN, 1995, p. 32). as palavra do diálogo da cena determinam e são determinadas pelas várias e diferentes vozes (heteroglossia) da linguagem sócio-ideológicas ressonantes na relação entre Vinícios e o Delegado.

Ainda nesta cena, o delegado o leva ao banheiro da delegacia e, no momento em que está urinando, pede o retrato de Eunice, recebendo-o das mãos de Vinícius, com uma das mãos. 0 delegado reclama de ser foto $3 \times 4$, deixando-a cair em seguida.

$O$ retrato é focalizado em meio à urina em PD. Vinícius junta-o com delicadeza e o entrega novamente ao delegado. O delegado comenta: - Você já procurou nos motéis?...: Vinícius afirma: - A minha Nicinha não é desse tipo, não...: O delegado reitera sua suspeita: - Bonito, mas quem some desse jeito só pode estar na contravenção... Eu vou te ajudar a encontrar a tua piranha, quer dizer a tua noiva.

O antagonismo, a dicotomia resultante destes planos e dos diálogos mostram novamente que: "cada signo ideológico é não apenas um reflexo, uma sombra da realidade, mas também um fragmento material dessa realidade." (BAKTHIN, 1995, p. 32) As cores da cena, sujeira do ambiente, o retrato boiando na urina recém depositada pelo delegado e a delicadeza de Vinícius, ao pegar o retrato, olhando-o com ternura funcionam como signos idelógicos, registrados, também, ainda na cena no banheiro, onde o delegado fixa a foto de Eunice, na região genital de uma moça nua de um pôster, fixado na parede, sobreposto a outros a também com o mesmo tema. No dialogo, Vinícius reporta-se ao delegado através do pronome "Você". O Delegado, por sua vez, o repreende, afirmando - Você não, Senhor, sou autoridade...Se você conhecesse alguém do ramo ajudava/Vinícius: -Alguém do ramo?/Delegado: —É dá prostituição... da vida, putas, garoto!

Mais tarde, na cena, em PD, Vinicius coloca a foto numa cerveja, em um grotesco bar do subúrbio. A foto é para Vinícius e o Delegado, "a concentração de vozes multidiscursivas dentre as quais deve ressoar a sua voz, essas vozes criam o fundo necessário para a sua voz." (BAKHTIN, 1995, p. 38). Fora de todo este contexto, tais vozes não seriam perceptíveis. Há todo um discurso sócio-ideológico perpassando (envolvendo) por este objeto, dialogando com as personagens da cena.

Seguindo sua odisséia, Vinícius vai até um prédio da periferia, onde Eunice morava com seus pais. No elevador, encontra Oliveira, pai de Eunice (Zé Trindade), um senhor aposentado e pobre. O pai diz seu nome soletrando-o ironicamente "o, de otário". Ainda nesta cena este vende um poema de Eunice a Vinícius, cujos versos apresento abaixo:

"É preciso que a ternura triunfe sobre o terror/E que de cordura não se morra mais, em nome do amor."

Segundo Bakthin: "cada enunciado concreto, seja ele prático ou poético, é um ato social, no fundo um evento histórico infinitesimal. Bakhtin propõe um processo dialético através do qual o extrínseco trocam constantemente de lugar." (STAN, 1992, p. 29) O diálogo, enquanto ato social expressa através deste elemento(versos), o intrínseco, as antíteses de Eunice. 
Na cena seguinte, Vinícius encontra mãe de Eunice (Mirian Pires), e esta apresenta em meio a um diálogo, quase monólogo (nervoso, confuso), frases antagônicas: Mãe de Eunice "... Eu e minha filha somos muito unidas, ela me conta tudo/Eunice nunca teve amigas/Sempre viveu muito sozinha/Eu nem sabia que ela tinha um namorado/Eu fui uma mãe exemplar/Depois de tanto estudo/minha filha é muito preparada/na escola era uma das primeiras da turma/Quando nasceu eu já passava dos quarenta/Todo mundo dizia que ela ia ser retardada/Eunice é um gênio/Conhece tanta gente é muito popular" Toda a contradição das palavras dos pais de Eunice remetem à ironia e esta ainda, ao carnavalesco, à máscara, pela própria ambigüidade estabelecida, ocultando faces, na sutileza dos disfarces. O disfarce, a máscara, remonta às próprias fontes da arte já afirmada como mimésis, por Aristóteles. Mimésis que não é simples imitação, mas sim transfiguração, máscara do real. E refiro-me, aqui, às fontes orientais (indo-européias) da Literatura, aos fabulários em que os homens, não tendo a coragem de assumir seus defeitos, transferiam-nos para os animais, investidos como "persona", máscaras do comportamento humano, Eunice usava máscara sobre máscara.

Seguindo na linearidade/diegese, em um bar um "Bêbado" (José Wilkner) paga Vinícius para tocar para ele. Vinicius aparece sentado na calçada da rua. Depois deposita o dinheiro ganho em cima da foto da primeira comunhão de Eunice, que ele havia retirado da casa de seus pais. Novamente instaura-se a dicotomia sacro/profano, estabelecendo uma relação dialógica entre a Eunice (Vinícius) Eunice (outros).

Nas cenas em que segue sua busca, Vinícius, em uma favela de um alagado, observa uma menina com roupa branca, que a avó denomina Santinha. A criança esta sendo amarrada a uma cruz, realizando um pseudo milagre de exorcismo em um negro que dizia possuído (Paulão). Vinícius percebe que a troca de olhares entre exorcista transita pelo desejo e pela ternura.

Mais tarde Vinícius retorna a favela do alagado, onde Santinha, após ser estuprada por seu exorcizado, repousa no colo da avó.

Ao ser localizado o estuprador, homem negro, reza para ser salvo à Santinha, e esta, fechando os olhos, "faz chover" arroz e feijão. A sobrevivência é a voz maior, e as pessoas esquecem do perseguido. Vinícius o salva, colocando-o em uma canoa que parte nas águas sujas.

Esta cena permite-nos retomar, novamente, o diálogo com a canção. Na canção: "Depois de navios negreiros/Outras correntezas/Estranho o teu Cristo/Que olha tão longe, além/Com braços sempre abertos/Mas sem proteger ninguém."

São versos marcados por uma profunda inquietante e dessacralizadora ironia. Do grego (ironeia) ironia tem seu significado transitando, também pela ironia socrática: modo de interrogar pelo qual Sócrates levava 0 interlocutor ao reconhecimento de sua ignorância. A força irônica desses versos situa-se no indagativo estranhamento com que o eu lírico se coloca em face do redentor abraço de Cristo. Na canção Cristo não cumpre o dever da proteção, tornando-se inútil, "sem proteger ninguém", porque tantos interlocutores do Amor, dele são ignorantes na essência do cotidiano.

Interrogação, sarcasmo, zombaria confluem para o mesmo sentido trágico da ironia: "tragédia do rumo perdido", numa interrogação-tentativa de "dar forma às ambigüidades e complexidades mutáveis da existência não idealizada." (FRYE, 1977, p. 218) 
A ironia, comportando sentido da auto-reflexividade, remete à intertextualidade, na medida em que evocam outros textos e deslocam dos mesmos a significação que contêm, no caso, aqui, de Castro Alves, no seu texto Navio Negreiro. Os grilhões são fortes, o contexto é novo, mas o tema é o mesmo. O irônico e ambíguo, estabelecem, portanto, um processo auto-reflexivo.

O novo texto engendrado pela canção/filme realiza um como enredar-se em si mesmo, donde as ambigüidades e interrogações de que se carrega. Tais interrogações traduzem o sentido trágico da existência, projetando a vida humana como uma servidão sem alívio e contra a qual o homem se rebela, numa atitude em que essa consciência pode transfundir-se em sarcasmo, zombaria.

A ambigüidade está presente na falsa Santinha, que salva seu agressor, enquanto na canção "Estranho o teu Cristo, Rio/Que olha tão longe, além/Com braços sempre abertos/Mas sem proteger ninguém." As personagens da cena, que buscam pateticamente o arroz e o feijão que caem do céu, ocupam o nenhum-lugar, observado pelo poeta e pelo olhar/câmera. A busca do trivial, essencial, entretanto, lugar como sobrevivência, condena ao nenhum-lugar, aguilhoando anseios. Paródia do Maná descido do céu, alimento/comunhão alentando a certeza do lugar a ser ocupado, a terra prometida, feijão e arroz significam o enquadramento ao lugar nenhum, à submissão, ao mero sobreviver.

No verso: "Neste filme como extras", conforme Bakthin, as formas do signo são condicionadas tanto pela organização social de tais indivíduos como pelas condições em que a interação filme e canção. (BAKTHIN, 1993, p. 44).

Nas cenas seguintes, Vinícius, apesar de não concordar, participa, como motorista, em um roubo a uma casa, com seu amigo Dreamer. O roubo não sai como Dreamer fala ao amigo. Dreamer: - ...um foguete que levasse a gente para as estrelas... like a dreamer..." Dreamer morre, e Vinícius chega à saída para a rua. Um som, em off do saxofone serve de fundo é ligação entre a agonia de Vinícius e sua apresentação, em conjunto com Cazuza, onde este o legitima como saxofonista, a partir de seu aplauso, que é seguido pelas demais personagens. É o restabelecimento da relação dialógica pessoa/personagem, ídolo/fã, subvertido pela relação personagem secundária/protagonista. E como um clipe, fornece sua música para o final da odisséia de Vinícius, que, ao encontrar, foge com Eunice, logo após saber, pelo delegado, que ela é traficante de drogas.

Vinícius salva Eunice, mas assim como Orfeu resgata Eurídice, ela vai embora, para o seu inferno. É a catarses de Vinícius.

Na cena final, Vinícius retorna "Orfeu", faz ouvir sua música, mas de que dilacerações se tem a melodia? " A vida do poeta tem ritmo diferente, segundo Vinícius de Moraes: "É um contínuo de dor angustiante/O poeta é o destinado do sofrimento/Do sofrimento que Ihe clariea a visão da beleza/E sua obra é uma parcela do infinito distante: $O$ infinito que ninguém sonda e ninguém compreende."

Na canção, os últimos versos: "Eu vou dar o meu desprezo/Pra você que me ensinou/Que a tristeza é uma maneira/Da gente se salvar depois", dessacralizam o mito de que o amor salva. Tal qual o filme, o que salva é o avesso: desprezo, tristeza. Isto enfeixando a dessacralização da dimensão absoluta do amor, que tudo suporta. 


\section{Referências}

BRAIT, Beth. A personagem. São Paulo: Ática. 2a ed.,1985

BAKTHIN, Mikail. Marxismo e filosofia da linguagem. São Paulo: Hucitec, 1995. 1993. Questões de literatura e estética: a teoria do romance. São Paulo: Hucitec,

CAZUZA. Boas Novas. Show de Sucessos. Imprensa, 1990.

FRYE, Nortroph. Anatomia da crítica. São Paulo: Cultrix, 1977

JULIEN, Nádia. Dicionário dos símbolos. São Paulo: Rideel, 1993

LANGER, Susanne K. A importância cultural da arte. São Paulo: Cultrix, 1981.

PALOTINI, Renata. Dramaturgia: construção do personagem. São Paulo: Ática, 1989.

STAM, Robert. Bakhtin - da teoria literária à cultura de massa. São Paulo:

Ática, 1992

FILMOGRAFIA: Um Trem para as Estrelas. Direção: Carlos Cacá Diegues, 1987.

\section{Title}

The Myth of Orpheus and Um trem para as estrelas: song and film

\section{Abstract}

This study analyzes the transit of the myth of Orpheus, based on those inter and intratextual aspects in the works Um Trem para as Estrelas (song and film). The theoretical frame is based on reflections on literary and cinematographic languages, with an emphasis on Bakhtinian theories on heteroglossia, dialogism, polyphony and carnivalization. The film Um Trem para as Estrelas (1987), by director Carlos (Cacá) Diegues presents the odyssey of Vinicius/Vina (Guilherme Fontes) in search of his beloved Eunice/Nicinha (Ana Beatriz Witgen), as well as his acclaim as a musician. The song "Um Trem para as Estrelas" was composed by Cazuza and Gilberto Gil, to be included in the film's sound track. In the analysis here made one also evaluates the presence of the persona of Cazuza, as he performs as himself in the film. One also calls attention to the irony that appears in both works. Through the consonance verse/scenes one perceives the peculiar way in which the Myth of Orpheus appears in the poem/song and film/images.

\section{Keywords}

Myth of Orpheus. Music. Cinema. 